\title{
Erratum To: Experts Opinion on the Use of Normative Data for Functional Capacity Evaluation in Occupational and Rehabilitation Medicine and Disability Claims
}

\author{
Remko Soer • Michiel F. Reneman • \\ Monique H. W. Frings-Dresen • P. Paul F. M. Kuijer
}

Published online: 29 May 2014

(C) Springer Science+Business Media New York 2014

\section{Erratum to: J Occup Rehabil}

DOI 10.1007/s10926-014-9507-8

Unfortunately, the family name of one of the co-authors, P. Paul F. M. Kuijer was wrongly identified in the original publication. The family name of the author should read as 'Kuijer' and his first two initials are 'P.P.'.

The online version of the original article can be found under doi:10.1007/s10926-014-9507-8.

R. Soer $(\bowtie) \cdot$ M. F. Reneman

Center for Rehabilitation, University of Groningen, University

Medical Center Groningen, 30.002, 9750 RA Haren, The

Netherlands

e-mail: r.soer@umcg.nl

R. Soer · M. F. Reneman

Groningen Spine Center, University of Groningen, University

Medical Center Groningen, Groningen, The Netherlands

R. Soer

Expertise Center of Health, Social Care and Technology, Saxion

Universities of Applied Sciences, Enschede, The Netherlands

M. H. W. Frings-Dresen - P. P. F. M. Kuijer

Coronel Institute of Occupational Health, Academic Medical

Center, University of Amsterdam, Amsterdam, The Netherlands 